\title{
The effect of transformational leadership on innovative work behavior with psychological capital as the mediating variable
}

\author{
R. Febita \\ Universitas Indonesia, Central Jakarta, DKI Jakarta, Indonesia \\ P.M. Desiana \\ Universitas Indonesia, Depok, West Java, Indonesia
}

\begin{abstract}
Innovation is very important for the sustainability and success of the company. Therefore, organizations should consider improving the employees' innovative work behavior. This study aims to examine the relationship between transformational leadership and the innovative work behavior of employees. This study used a mediation process to uncover the mediating impact of psychological capital in the proposed model. Furthermore, it used cross-sectional design and administered a questionnaire to 285 employees working at a major information and communication technology company in Indonesia (PT XYZ) to assess the proposed relationships. SPSS 25 and Lisrel 8.8 were used for statistical analysis. The result showed that psychological capital mediated the relationship between transformational leadership and innovative work behavior. Thus, the study shows that transformational leaders improved their employees' innovative work behavior by improving their psychological capital.
\end{abstract}

\section{INTRODUCTION}

Innovation is the most important factor for many organizations in the business environment. Correspondingly, previous studies show that organizational innovation exists only when employees have innovative work behavior. Organizational innovation is built on new ideas, which are generated, promoted, and implemented by employees. Therefore, organizational innovation depends on employee innovative work behavior (Amankwaa et al. 2019).

PT XYZ is a major information and communication technology (ICT) company in Indonesia. PT XYZ is demanded to provide quality and fast services, so that innovation continues to be carried out in terms of both internal and external processes, especially in the field of digital telecommunications. So far, PT XYZ's digital business is considered not enough to compete with other competitors, especially with foreign companies.

Psychological capital has a positive and significant effect on creativity and innovative behavior (Lei et al. 2020). Psychological capital is a person's positive psychological state, which is categorized by self-efficacy, optimism, hope, and resilience (Luthans et al. 2007). Individuals who have high psychological capital will try to come up with creative ways to achieve their goals (Abbas \& Raja 2015).

Transformational leadership is one of the most effective types of leadership and has a significant effect on the performance of subordinates (Le \& Lei 2018). Transformational leadership characteristics are the right driver to improve the four factors of psychological capital (Schuckert et al. 2018). Transformational leaders encourage company innovation through innovative behavior of employees to create innovative ideas and implement these innovative ideas into new products or processes (Birasnav et al. 2011). However, empirical studies show different results regarding its effects on innovative behavior; some show a significant relationship (Afsar \& Umrani 2019; 
Amankwaa et al. 2019), others an insignificant one (Pundt 2015; Bednall et al. 2018). Leadership is very important aspect in PT XYZ. Therefore, a lot of training programs related to leadership have been carried out.

There are a few studies on the relationship of psychological capital with innovative work behavior (Schuckert et al. 2018; Lei et al. 2020). Based on the aforementioned explanation, the authors are interested in conducting research on the innovative work behavior of PT XYZ employees to examine whether transformational leadership can directly and indirectly increase innovative work behavior, with psychological capital as the mediating variable.

\section{LITERATURE REVIEW}

Transformational leadership characteristics are identifying and communicating vision, taking action that should be used as an example, encouraging acceptance of team goals, improving team performance, providing support for employees, and stimulating employee intelligence (Carless et al. 2000). Meanwhile, innovative work behavior consists of three different behavioral tasks for innovation, namely, idea generation, idea promotion, and idea realization. The first task is idea generation, which is creating novel and useful ideas. The next task is idea promotion, which is engaging in social activities to build supporters who provide the power to realize the ideas. The final task is idea realization, which is producing a model or prototype of the innovation (Janssen 2000). Transformational leaders build enthusiasm among organizational members to be more creative, as well as to create new ideas and solutions related to organizational structure, processes, and implementation (Afsar \& Umrani 2019). Schuckert et al. (2018) showed that transformational leadership has a positive and significant effect on innovative work behavior. Thus, in this study, the first hypothesis is as follows:

H1: Transformational leadership has a positive and significant effect on innovative work behavior of employees.

Psychological capital is a person's positive psychological condition, which is categorized by four factors. These factors are self-efficacy, optimism, hope, and resilience (Luthans et al. 2007). Logically, the characteristics of transformational leadership are the right drivers to improve the four factors of psychological capital (Schuckert et al. 2018). Transformational leaders can affect the psychological capital of their subordinates because they can influence the beliefs, values, and goals of their subordinates (Wang et al. 2018). Schuckert et al. (2018) proved that transformational leadership has a positive and significant effect on psychological capital. Thus, the second hypothesis of this study is as follows:

H2: Transformational leadership has a positive and significant effect on psychological capital of employees.

Individuals who have high self-efficacy will have high intrinsic motivation, self-confidence, and intelligence, and they dare to face challenging and creative situations (Mishra et al. 2017). Optimistic individuals will not give up easily, and they have a positive view in stressful conditions. Thus, they will look for creative ways to solve problems and take advantage of every opportunity (Rego et al. 2012). Individuals who have high hope see problems and opportunities from different perspectives and look for creative ways to solve problems (Mishra et al. 2017). Resilience is also important when they are undergoing activities that require long-term effort, while maintaining high efficiency (Wojtczuk-Turek \& Turek 2015), such as innovation activities. Mishra et al. (2017) showed that psychological capital has a positive and significant effect on innovative work behavior. Thus, the third hypothesis is as follows:

H3: Psychological capital has a positive and significant effect on innovative work behavior of employees. 
In this study, the authors intended to test the mediating effect of psychological capital on the relationship between transformational leadership and innovative work behavior. Thus, the fourth hypothesis is as follows:

H4: Psychological capital mediates the relationship of transformational leadership and innovative work behavior.

\section{RESEARCH METHODS}

The participants of this study are 285 employees working for a major information and communication technology (ICT) company in Indonesia. The authors informed potential participants that the questionnaire was confidential and anonymous. The participants were asked to rate on their supervisors' transformational leadership characteristics, psychological capital, and their innovative work behavior. From 285 participants, $53.33 \%$ were male, $64.56 \%$ completed a bachelor's degree, $41.40 \%$ have been working for four up to six years in this company, and $55.49 \%$ have staff positions. $35.09 \%$ of the participants were from sales and marketing, $34.74 \%$ were from operations, and the rest were from other departments.

The authors used a six-point Likert scale ranging from (1) "strongly disagree" to (6) "strongly agree" for transformational leadership and psychological capital indicators and (1) "never" to (6) "very often" for innovative work behavior indicators. A seven-item scale reported by Carless et al. (2000) was used to measure transformational leadership behavior. Meanwhile, a scale reported by Luthans et al. (2007) was used to measure employee's psychological capital. The dimensions were self-efficacy, optimism, hope, and resilience; each dimension has six items, so there are 24 items. Innovative work behavior was rated using Janssen (2000)'s nine-item measure. The dimensions include idea generation, idea promotion, and idea realization; each dimension has three items.

\section{RESULTS}

Data were analyzed using the structural equation modeling (SEM) approach with Lisrel 8.8. The authors dropped three items from psychological capital because they did not meet the validity requirements. Thus, the authors only used 21 scales for psychological capital measurement. The results of data collection that have met the standards of validity and reliability were used for data processing.

The direct relationships among the core constructs in the theoretical model used one-tailed test method with a 95\% confidence level. Transformational leadership $(\beta=0.07, \mathrm{p}<0.05)$ does not have a significant effect on innovative work behavior; so H1 was rejected. In addition, transformational leadership $(\beta=0.42, \mathrm{p}<0.05)$ has a positive and significant effect on psychological capital; so $\mathrm{H} 2$ was supported. Psychological capital $(\beta=0.71, \mathrm{p}<0.05)$ has a positive and significant effect on innovative work behavior; so $\mathrm{H} 3$ was also supported.

The value of the mediating effect $(0.37)$ is greater than the direct effect $(0.07)$, indicating that psychological capital strengthens the relationship between transformational leadership and innovative work behavior. The authors also used Sobel (1982) Z-test to test the mediation effect. Z-value for the mediating effect of psychological capital on transformational leadership and innovative work behavior relationship is 6.28 with a p-value of zero. This result shows that psychological capital mediates the relationship between transformational leadership and innovative work behavior, and so $\mathrm{H} 4$ was supported.

\section{CONCLUSION}

In conclusion, our study clarifies the mechanism by which transformational leadership influences innovative work behavior with psychological capital as the mediating variable. Transformational 
leaders can convince employees to think positively in terms of new visions and ideas. Thus, employees are not only more confident in their abilities but also more optimistic in their actions and in thinking about the future. Therefore, they can motivate employees to be more innovative (Lei et al. 2020). In other words, the characteristics in transformational leadership are the right drivers for increasing psychological capital, which is also a driver for innovative behavior (Schuckert et al. 2018).

Our study suggests several practical implications from strategic and operational levels to increase innovative work behavior of employees. From the strategic level, management should consider creating a pleasant work environment to create positive employee emotions, so that psychological capital of employees can be improved. Management also should consider using transformational leadership measurement in training and promotion programs. From the operational level, supervisors and managers should preach what they have taught to their subordinates. In addition, they should instill pride and respect in others and inspire their subordinates to be more competent.

This study has certain limitations that can be fixed in the future research. First, as our data came from only one company, the result can be different if applied on the industrial level. A sample of employees on the industry level may extend our findings. Second, the research data were distributed through an online questionnaire. This resulted in the decision to fill out the questionnaire depending on the willingness of the respondent, and so the distribution of the results of this study was not even for each group of respondents. For the next research, it is better to distribute the questionnaires offline.

\section{REFERENCES}

Abbas, M., \& Raja, U. 2015. Impact of psychological capital on innovative performance and job stress.

Canadian Journal of Administrative Sciences/Revue Canadienne des Sciences de l'Administration 32(2): $128-138$

Afsar, B., \& Umrani, W. A. 2019. Does thriving and trust in the leader explain the link between transformational leadership and innovative work behaviour? A cross-sectional survey. Journal of Research in Nursing 25(1): $37-51$.

Amankwaa, A., Gyensare, M. A., \& Susomrith, P. 2019. Transformational leadership with innovative behaviour. Leadership \& Organization Development Journal 40(4): 402-420.

Bednall, T. C., E. Rafferty, A., Shipton, H., Sanders, K., \& J. Jackson, C. 2018. Innovative behaviour: how much transformational leadership do you need?. British Journal of Management 29(4): 796-816.

Birasnav, M., Rangnekar, S., \& Dalpati, A. 2011. Transformational leadership and human capital benefits: The role of knowledge management. Leadership \& Organization Development Journal 32(2): 106-126.

Carless, S. A., Wearing, A. J., \& Mann, L. 2000. A short measure of transformational leadership. Journal of business and psychology 14(3): 389-405.

Janssen, O. 2000. Job demands, perceptions of effort-reward fairness and innovative work behaviour. Journal of Occupational and Organizational Psychology 73(3): 287-302.

Le, P. B., \& Lei, H. 2018. The mediating role of trust in stimulating the relationship between transformational leadership and knowledge sharing processes. Journal of Knowledge Management 22(3): 521-537.

Lei, H., Leaungkhamma, L., \& Le, P. B. 2020. How transformational leadership facilitates innovation capability: the mediating role of employees' psychological capital. Leadership \& Organization Development Journal 41(4): 481-499.

Luthans, F., Youssef, C.M. \& Avolio, B.J. 2007. Psychological Capital: Developing the Human Competitive Edge. New York: Oxford University Press Oxford.

Mishra, P., Bhatnagar, J., Gupta, R., \& Wadsworth, S. M. 2017. How work-family enrichment influence innovative work behavior: Role of psychological capital and supervisory support. Journal of Management and Organization 25(1): 58-80.

Pundt, A. 2015. The relationship between humorous leadership and innovative behavior. Journal of Managerial Psychology 30(8): 878-893.

Rego, A., Sousa, F., Marques, C., \& e Cunha, M. P. 2012. Authentic leadership promoting employees' psychological capital and creativity. Journal of business research 65(3): 429-437. 
Schuckert, M., Kim, T. T., Paek, S., \& Lee, G. 2018. Motivate to innovate How authentic and transformational leaders influence employees' psychological capital and service innovation behavior. International Journal of Contemporary Hospitality Management 30(2): 776-796.

Sobel, M. E. 1982. Asymptotic confidence intervals for indirect effects in structural equation models. Sociological methodology 13: 290-312.

Wang, Y., Zheng, Y., \& Zhu, Y. 2018. How transformational leadership influences employee voice behavior: The roles of psychological capital and organizational identification. Social Behavior and Personality: an international journal 46(2): 313-321.

Wojtczuk-Turek, A., \& Turek, D. 2015. Innovative behaviour in the workplace. European Journal of Innovation Management 18(3): 397-419. 